\title{
El trabajador social de la Administración de Justicia española en los procesos de rupturas matrimoniales
}

\author{
Social Worker Performance in the Spanish Administration of Justice on \\ Marital Breakdown Processes \\ O trabalhador social da Administração de Justiça espanhola nos processos \\ de rupturas matrimonias
}

\author{
FRANCISCO GÓMEZ GÓMEZ* \\ RAÚl SOTO ESTEBAN ${ }^{* *}$
}

FECHA DE RECEPCIÓN: 28 DE NOVIEMBRE DE 2014. FECHA DE ACEPTACIÓN: 13 DE ABRIL DE 2015

Doi: dx.doi.org/10.12804/esj 17.02.2015.06

Para citar este artículo: Gómez, Gómez, F., \& Soto Esteban, R., (2015). El trabajador social de la Administración de Justicia española en los procesos de rupturas matrimoniales. Estudios Socio-jurídicos, 17(2), 131-166. Doi: dx.doi.org/10.12804/ esj17.02.2015.06

\section{RESUMEN}

Los Juzgados de Familia de Madrid y Barcelona disponen de trabajadores sociales para ayudar al juez en las decisiones sobre asuntos de familia. Estos profesionales cumplen su función en el SATAF (Servei d'Assesorament Técnic en l'Ámbit de Familia) en Barcelona y los equipos psicosociales en Madrid. Este estudio busca develar una situación real escondida en polémicas y debates científicos y populares. El estudio busca también conocer cómo se sitúa el trabajador social del ámbito de justicia.

Palabras clave: lugar (relevancia, rol, poder) del trabajo social en el ámbito de justicia, prueba pericial, función auxiliar, psicosocial, familias.

* Doctor en Ciencias Políticas y Sociología por la Universidad Complutense de Madrid (UCM). Profesor titular de la Universidad Complutense de Madrid, Departamento de Trabajo Social y Servicios Sociales, Facultad de Trabajo Social. Correo electrónico: fgomez@ucm.es

** Doctorando en Trabajo Social de la Universidad Complutense de Madrid. Trabajador Social de los juzgados de primera instancia e instrucción de Alcobendas (Madrid). Este artículo se deriva del proyecto de tesis doctoral en Trabajo Social referido a la administración de Justicia. Correo electrónico: raul.soto@algoasi.com 


\section{ABSTRACT}

The Family Courts in Madrid and Barcelona have social workers to assist the judge in deciding on family matters. These professionals do their job in the SATAF (Servei d'Assesorament Técnic en l'Ambit de Family) in Barcelona and Madrid Psychosocial Teams. This study seeks to unveil a real situation which has been hidden in controversies as well as scientific and popular debates. The study also seeks to understand how social workers in the field of justice are placed in that reality.

Keywords: Location (relevance, role, power), social worker in the field of justice, expert evidence, auxiliary function, psychosocial, families.

\section{RESUMO}

Os Tribunais de Família de Madrid e Barcelona dispõem de trabalhadores sociais para ajudar ao juiz nas decisões sobre assuntos de família. Estes profissionais cumprem sua função no SATAF (Servei d'Assesorament Técnic en l'Ámbit de Familia) em Barcelona e as Equipes Psicossociais em Madrid. Este estudo busca desvelar uma situação real escondida em polémicas e debates científicos e populares. O estudo busca também conhecer como situa-se o trabalhador social do âmbito de justiça nessa realidade.

Palavras- chave: Local (relevância, rol, poder) de trabalho social no âmbito de justiça, prova pericial, função auxiliar, psicossocial, familias. 


\section{Introducción}

Este artículo nace de una investigación más amplia que traza mapas de presencias e influencias. Los trabajadores sociales existen en el ámbito de justicia en España desde 1982 y emiten informes que influyen en las decisiones judiciales y en la vida de las familias. Este lugar -entendido como rol, relevancia y poder- es relativo si atendemos a otras variables que se desarrollan en el estudio. Los autores realizan un amplio estudio sobre el lugar del trabajador social en el mundo pericial, Pilar Ruíz (2004, p. 16) recoge esta función como primordial: "El Trabajador Social actúa en la Administración de Justicia como Perito, interviene en los procesos judiciales tanto de manera individual como en equipo." Ruíz se refiere a las distintas formas en que los trabajadores sociales trabajan en la administración de justicia: en ocasiones de forma monodisciplinar, con técnicas de evaluación propias de su profesión y desarrollando informes sociofamiliares, y en otras ocasiones, compartiendo la evaluación con el psicólogo y emitiendo conjuntamente un informe psicosocial.

El ejercicio del derecho de familia, la tarea profesional de los equipos psicosociales o del trabajador social judicial y la propia dinámica de las familias en crisis son realidades complejas que necesitan explicarse. En este estudio se analizan los discursos de los protagonistas de la labor pericial psicosocial: jueces, psicólogos y trabajadores sociales. Los discursos fueron obtenidos a través de las técnicas de entrevistas y grupos de discusión, propias de la metodología de investigación cualitativa.

Los discursos deben ayudar a crear un mapa de la realidad estudiada. Las conclusiones de Solé (2009, p. 222) sobre las redes complejas inspiran este intento:

Entender lo complejo es una tarea difícil, pero hay un componente indispensable para ello: cuidarse bien de reducir el todo a las partes. (...) Desentrañar la arquitectura de las redes complejas no sólo nos permitirá trazar nuevos mapas de la realidad. Nos ayudará a reflexionar sobre los errores pasados y los retos futuros. La cartografía que nos revelan estas redes será un elemento esencial en los viajes que deberemos emprender hacia un conocimiento mejor, pero también más responsable, de este mundo único y frágil en el que nos ha tocado vivir. 
Los discursos de los protagonistas hablan de su situación profesional, ya que el lugar del equipo psicosocial es un paso previo para conocer la propia ubicación del trabajo social en el ámbito de justicia. Marta Simón (2010, p. 183) lo expresa de forma clara: "La metodología de trabajo interdisciplinar exige profundizar sobre las aportaciones específicas de cada disciplina y, en concreto, de los profesionales que conforman el equipo."

\section{El Estado del arte}

Este artículo parte de un debate entre profesionales en torno a la pregunta, ¿qué lugar ocupa el trabajador social en el ámbito de justicia? El lugar entendido como influencia y situación.

El Magistrado de Familia González del Pozo (2007, p. 432) relata el inicio de esta realidad profesional:

El Ministerio de Justicia, ya en el año 1982 anunció la creación, a título experimental, de equipos de especialistas para los juzgados de familia de Madrid y Barcelona. La idea, sin embargo, no se materializó hasta noviembre de 1983, fecha en la que el Ministerio de Justicia, a propuesta del Consejo General del Poder Judicial, constituyó, a título de experiencia piloto, diecinueve equipos psicosociales, formados por un psicólogo y un asistente social, para los juzgados especializados en Familia existentes en aquella fecha (González del Pozo, 2007, p. 432).

En primer lugar, hay que señalar la falta de definición laboral. El trabajador social en el ámbito de justicia es personal laboral, una situación temporal distinta de la estabilización dentro de un cuerpo de funcionarios de ente nacional o regional; esta propuesta de establecer el cuerpo de trabajadores sociales forenses se planteó en una primera redacción de la Ley Orgánica 5/2000, de Responsabilidad Penal del Menor, aunque se retiró del texto legal definitivo.

Tampoco existe una determinación funcional, más allá de la recogida en la Guía de Actuación de los Trabajadores Sociales, en el ámbito de la administración de justicia de la Comunidad de Madrid o las aportaciones de juristas: 
En los procedimientos de separación, divorcio, juicio verbal sobre guarda y alimentos, juicio verbal sobre régimen de visitas y en modificación de medidas, el objeto versará sobre:

- Capacidad socio-familiar para asumir el cuidado y atención de los hijos a fin de recomendar el ejercicio de la guarda y custodia a uno de los progenitores, a los dos conjuntamente o a un tercero en el supuesto de que ninguno de ellos reúna las condiciones para ello.

- Seguimiento de casos en los que concurran circunstancias que requieran un proceso de adaptación a la nueva situación familiar, después de establecerse las medidas judiciales y en los supuestos que pudieran conllevar algún riesgo para el menor.

- Conveniencia de fijar o establecer un régimen de visitas o modificarlo cuando ya esté establecido (ampliándolo, suspendiéndolo o restringiéndolo) entre los progenitores y los hijos, entre los hermanos en los supuestos de convivencia separada y entre los menores y la familia extensa (Guía, 2006).

El Fiscal López Ordiales (2008) recoge las conclusiones de la II Jornada de jueces y magistrados de familia e incapacidades (septiembre de 2004), algunas de ellas referidas a lo que se espera de los equipos psicosociales, en concreto la sexta:

$6^{\mathrm{a}}$. La actuación de los equipos psicosociales no solo se ha de centrar en la elaboración del correspondiente informe técnico (...) sino que además podrán desarrollar otras complementarias como:

- Prestar ayuda puntual a la familia para afrontar la crisis familiar.

- Informar de la existencia de instrumentos alternativos para la solución de los conflictos relacionados con una crisis familiar, como lo es la mediación, que evitarían el procedimiento judicial contencioso y con los que se podrían obtener acuerdos sólidos y solventes.

- Otras labores de seguimiento y apoyo.

- Coordinación con los puntos de encuentro, etc... (2008, p. 270).

Los equipos psicosociales a los que pertenece el trabajador social tampoco existen en la ley de una forma clara y explícita ni en las leyes 
procesales, ni en las que tratan de la resolución de las rupturas familiares. La crítica del letrado Zarraluqui (presidente de la Asociación Española de Abogados de Familia), que ante la Comisión de Justicia del Congreso de los Diputados explicó sobre estos profesionales:

El equipo psicosocial no está en la Ley, no existe (...). El equipo psicosocial es un funcionario fantasma del Ministerio de Justicia (...) que ni en la Ley Orgánica ni en la ley procesal está (...). Tendríamos que inventarlos y darles cabida en la Ley porque hacen un papel fundamental (En Hijas, 2007, p. 433).

Tan sólo el Código Civil de Cataluña aporta una reseña en su artículo 92, disposición adicional sexta punto 4 del libro II, ${ }^{1}$ que tiene una presencia marginal en el ámbito catalán (Ley 25/2010, de 29 de julio, del libro segundo del Código civil de Cataluña, relativo a la persona y la familia). ${ }^{2}$

El desarrollo de un discurso, de una documentación producto del trabajo de más de treinta años en España (1982-2015) es escaso. Entre los trabajos destacados se encuentran los de Ruíz (2004); Simón (2010); Alcázar (2014); Gómez y Soto (2015) y solo la aportación foránea de Robles (2004); Adlay, Ramjklac y Nicolini (2001); Davis (2007); Maschi y Killian (2009) entre otros, completa esta carencia.

\section{Planteamiento de la cuestión}

Las decisiones judiciales sobre asuntos de familia ya no se someten a criterios objetivos y claros. Antiguamente, existían criterios objetivos como

1 El artículo 92.6 de la Ley 15/05 establece que: En todo caso, antes de acordar el régimen de guarda y custodia, el juez deberá recabar informe del Ministerio Fiscal y oír a los menores que tengan suficiente juicio cuando se estime necesario de oficio o a petición del Fiscal, partes o miembros del Equipo Técnico Judicial, o del propio menor. (Código Civil de Cataluña, 2005).

2 El punto 4 de la Ley 25/10. D.A., establece que los especialistas integrados en los equipos técnicos que apoyan a los tribunales o los designados en lugar de aquellos son auxiliares de los tribunales. Las autoridades y los organismos públicos y privados, y los profesionales que hayan intervenido previamente con la familia, tienen el deber de colaborar. Si la colaboración solicitada se refiere a aspectos protegidos por el secreto profesional, por el derecho de intimidad o por la normativa relativa a datos personales, se requiere una resolución expresa del tribunal (Código Civil de Cataluña, 2005). 
la concesión de custodias maternas en los menores de siete años. En la actualidad, la evolución de la familia española indica un cambio de roles y una mayor igualdad entre sus miembros (Alberdi, 1995, 1999; Iglesias de Ussel y Ayuso, 2007). La propia evolución de los sistemas familiares los ha vuelto complejos e inabordables desde una mirada jurídica única. A partir de este cambio, los jueces buscan conocedores, peritos, expertos; a veces prefieren auxiliares o consejeros. La realidad es que las decisiones se abren a situaciones difíciles de diagnosticar sin un criterio técnico definido. En los años ochenta surgieron los equipos psicosociales para llenar ese vacío de discrecionalidad y duda en el que los jueces se ven cuando la decisión sobre la futura organización familiar no se acuerda por los padres y se complica por criterios humanos y sociales.

\section{Metodología}

La metodología es la propia de una investigación que busca develar, descubrir y explorar más que demostrar, por lo que se escogió, por lo menos inicialmente, la metodología cualitativa. El método cualitativo será el utilizado en esta investigación, pues como afirma Beltrán (2007) la especie humana es la única que vive en una realidad material y simbólica. Por su parte, Del Val y Gutiérrez (2005) explican que es un tipo de investigación basado en el potencial de búsqueda heurístico. La concepción de esta sociedad como compleja, justifica que se le estudie de forma novedosa y abierta, sin los corsés del método científico, propio de las ciencias naturales.

El interés del estudio son los discursos de sus protagonistas y sus percepciones en relación con el devenir profesional. Por ello, la investigación se centrará en la evaluación de significados y empleará técnicas cualitativas como entrevistas abiertas y grupos de discusión triangulares.

Para Murillo y Mena (2006), el objetivo de la perspectiva cualitativa es captar las diferentes formas de nombrar la sociedad por parte de los individuos, tomando a estos como actores sociales y no como sujetos aislados, puesto que las opiniones particulares son deudoras del sistema al cual se inscriben. El principal material es el lenguaje, no solo como vehículo de expresión, sino como práctica social. 
La profesora argentina Irene Vasilachis refiere que: "Las investigadoras y los investigadores cualitativos se interesan por la manera en que la complejidad de las interacciones sociales se expresa en la vida cotidiana y por el significado que los actores atribuyen a esas interacciones" (2006, p. 34). Y cita a Gobo (2005) "Los métodos cualitativos se caracterizan por su ostensible capacidad para describir, comprender y explicar los fenómenos sociales".

\section{Mapa de elementos}

El estudio general parte de un mapa de elementos (Murillo y Mena, 2006) que supone el primer dibujo de la situación (figura 1):

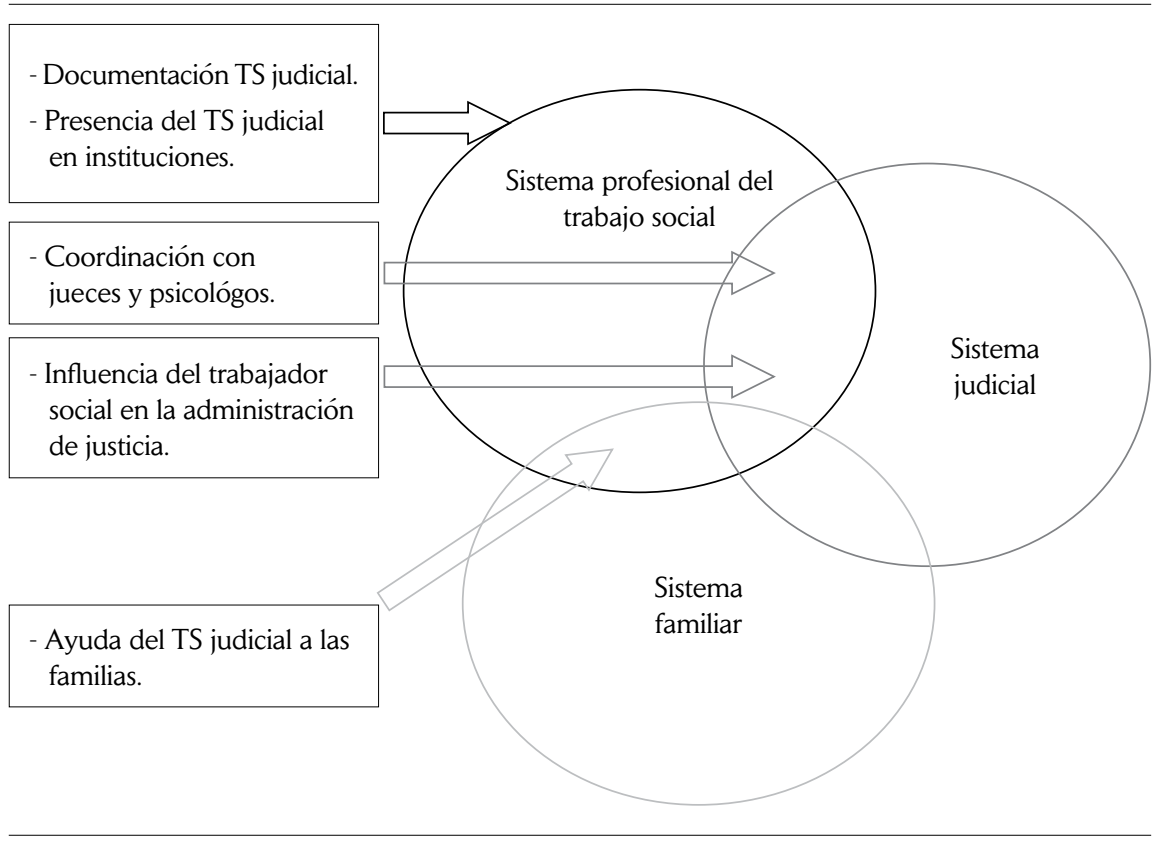

Figura 1. Mapa de elementos

Fuente: elaboración propia con base en Murillo y Mena, (2006).

Este mapa de elementos en la terminología de Murillo y Mena (2006) da lugar a una serie de indicadores para valorar o evaluar. En este trabajo 
de investigación se recoge el primero de ellos que se desarrollará en este artículo:

- La influencia del trabajo social en la administración de justicia y en las decisiones judiciales vivida desde el propio discurso de los trabajadores sociales, pero también en el de los profesionales cercanos (los propios jueces, los psicólogos, etc.).

Este indicador se concreta y se hace evaluable a través de variables:

- El discurso de los profesionales del trabajo social-judicial u otros profesionales cercanos, debe contener estas variables en un sentido presente o ausente:

- Las solicitudes del trabajo pericial social. El oficio es el documento en el que el juez solicita al trabajador social la evaluación pericial. Es pertinente evaluar cómo entienden los profesionales que se hace esta solicitud al equipo psicosocial en conjunto, al psicólogo o al trabajador social y las razones de ello.

- Las referencias en las sentencias judiciales derivan de las valoraciones sociales. Así es como los profesionales han visto que se refleja el resultado de la evaluación pericial en las sentencias judiciales.

- La comprensión de la diferencia de la evaluación social respecto a la de otros profesionales.

- La expresión del trabajo en equipo como necesario o no. El trabajador social forma parte de equipos psicosociales, pero cómo se lleva a la práctica esta realidad.

E intenta demostrar el siguiente supuesto previo:

- Las solicitudes de ayuda pericial social de los jueces indican que esta les sirve para tomar sus decisiones, al encontrar en los informes sociofamiliares nuevos criterios para valorar las decisiones relativas a la resolución de crisis matrimoniales. 


\section{Objetivos}

Objetivo general:

- Develar la trascendencia (importancia, lugar e influencia) de la tarea pericial social en los procesos judiciales sobre crisis familiares.

Objetivos específicos:

- Investigar la evolución de la intervención del trabajo social en España con familias en los últimos veinticinco años.

- Estudiar la dinámica profesional del trabajo social en el ámbito jurídico en derecho de familia.

- Conocer la relación entre el perfil profesional del trabajador social y su tarea pericial en los Juzgados de Familia.

- Describir las consecuencias de este trabajo en los jueces de familia y en sus decisiones.

La metodología descrita en este artículo constituye la primera parte de la investigación, en la cual se traza el mapa de situación; luego la investigación hablará con las familias y planteará opciones de futuro.

Este texto discurre en el análisis de discursos de especialistas: jueces, psicólogos y trabajadores sociales, tomados individualmente en entrevistas o en grupos de discusión triangulares, para luego analizarlos y situarlos con respecto a una intención inicial. Las entrevistas se realizaron entre enero de 2011 y enero de 2012. Los grupos de discusión triangulares se realizaron posteriormente, durante 2012. El estudio pretende comparar ambas realidades con el mismo repertorio técnico. Se elaboró un modelo de entrevista que varía para cada área profesional: jueces, profesores universitarios, psicólogos o trabajadores sociales, aplicado en Madrid y Barcelona. El protocolo del grupo de discusión varía según profesión.

La primera etapa se llevó a cabo, principalmente, en las provincias de Madrid y Barcelona. Esta elección obedeció a la concentración de profesionales en las dos ciudades y su periferia metropolitana, lo que facilitó la implementación de las diferentes técnicas. 


\section{Las técnicas}

\subsection{La entrevista cualitativa}

La entrevista es un proceso en el cual el investigador extrae información del entrevistado, que procede de su propia biografía.

Alonso (1994) considera que "la técnica de la entrevista abierta se presenta útil, por lo tanto, para obtener información de carácter pragmático, es decir, de cómo los sujetos diversos actúan y reconstruyen el sistema de representaciones sociales en sus prácticas individuales" (p. 226).

Dentro de la entrevista, la gestión de las preguntas debe priorizar aquellas que se refieren a lo que el individuo hace o hizo en relación con el objeto de la investigación, no solo a lo que piense sobre este objeto. Es interesante que las entrevistas puedan servir de complemento de los grupos de discusión, los cuales obtienen representaciones de tipo colectivo, distintos de la dimensión pragmática personalizada de la entrevista.

Del Val y Gutiérrez Brito (2005), por su parte, consideran que la entrevista requiere de una preparación previa por parte del investigador, ya que el objetivo es lograr una buena empatía con el entrevistado, sin participar en exceso en su desarrollo. Además, ambas partes deben hacer un trato para resolver la paradoja de tener que hacer públicas sus opiniones privadas.

\subsection{El grupo de discusión triangular}

El número de grupos que van a participar en la investigación es variable. Serán trabajadores sociales que trabajan o han trabajado con crisis familiares en los juzgados de Madrid y su periferia. En principio, se confeccionarán grupos triangulares, es decir, de tres miembros. Motivado por la condición de expertos de los profesionales y la dificultad de juntar grandes grupos en una población limitada, Roldán propone esta nueva técnica "interesante dentro del enfoque cualitativo, y que constituye una posición intermedia entre las entrevistas personales y los grupos de discusión" (1998, p. 137). Para Ortí estos grupos:

Constituyen un espacio social y simbólico de mediación entre las entrevistas abiertas personales (más orientadas hacia la expresión/captación 
de la estructura profunda y singular de cada arquetipo de personalidad) y la tradicional práctica de los grupos de discusión (Ortí, 1993, citado en Roldán, 1998, p. 137).

El número de profesionales que participó en esta investigación se estableció considerando continuos cambios laborales y un mínimo margen de error de apreciación. En Barcelona había ocho trabajadores sociales y dieciséis psicólogos para toda la provincia. En Madrid, había catorce psicólogos y catorce trabajadores sociales, y en la periferia, veintinueve psicólogos y veinte trabajadores sociales, de los cuales se entrevistó un total de treinta y tres profesionales: cuatro jueces de Madrid y cuatro de Barcelona, seis trabajadores sociales de Madrid y seis de Barcelona, cuatro psicólogos de Madrid y ocho de Barcelona, además de un profesor universitario de Madrid.

Se implementaron tres grupos de discusión triangulares: dos de trabajadores sociales y uno de psicólogos, ambos en Madrid. En Barcelona fue imposible llevar a cabo esta técnica debido a que todos los profesionales trabajan en el mismo lugar y se conocen, lo que impide una discusión nueva y creadora de discurso.

\section{Análisis de datos}

Valles (2007) se refiere al análisis clásico (el que plantea un sistema de evaluación similar al método cuantitativo) como una forma de aplicar los procedimientos de los datos cuantitativos a los cualitativos. Propone el método comparativo constante de Glaser como el más adecuado para el análisis cualitativo de datos, apoyado en los instrumentos de software, en el caso de esta investigación el programa ATLAS/ti, método seleccionado para este estudio sin perjuicio del empleo de elementos del análisis clásico. Glaser (en Valles, 2007) recoge los enfoques previos, uno a la inspección de datos y otro a la codificación, y propone un tercer sistema combinado, que deriva en la creación de teoría a través de la saturación de información. En primer lugar, el soporte informático hace anotaciones que se vinculan con el origen del estudio; luego en la medida en que se recogen estos datos, se analizan y, finalmente, a través de la codificación, se formulan preguntas y se hacen comparaciones. Este proceso es conocido como grounded theory. 
Teniendo en cuenta las particularidades del presente estudio, dada la escasez de textos previos sobre el tema y dentro de una lógica de inmersión en la cuestión, nos es posible realizar el análisis desde la perspectiva de la grounded theory. En el proceso se obtuvieron discursos principales para la resolución del objetivo, la información recopilada satura el estudio debido al número de participantes y a la condición de expertos de los entrevistados y llamados a debatir en grupos de discusión.

A continuación se presentan los pasos que orientaron el análisis de datos a la luz de la descripción de Valles (2007):

- De los datos brutos a la categorización inicial: una vez realizadas las entrevistas y los grupos de discusión, se llevó la transcripción de la información al programa ATLAS.ti y se creó la unidad hermenéutica correspondiente. Al mismo tiempo, se inició el proceso de codificación abierta, en el cual se desarrolla el muestreo y se buscan categorías que ayuden a comparar. La información se codificó por profesiones de las personas participantes tanto en las entrevistas como en los grupos de discusión, y por los temas generales que se indagan, asociados a los objetivos del estudio.

- Desarrollo de categorías iniciales: búsqueda de propiedades y registro de notas teóricas.

- Integración de las categorías, sus propiedades y su unión a las hipótesis.

- Delimitación de la teoría por el criterio de parsimonia o economía científica, por el que se hace máxima una explicación científica con un mínimo de conceptos y formulaciones, o el criterio de alcance que amplía el campo de aplicación de la teoría sin desligarse de la base empírica de partida.

- Escritura de la teoría con la publicación de resultados.

Los códigos que resultan de este proceso de codificación abierta ayudan a crear el discurso conjunto del total de participantes. Debido a que la distribución inicial de los participantes de este estudio - jueces, profesores, psicólogos o trabajadores sociales- no permitía una categorización de significados, se estableció como criterio de clasificación la cercanía en el discurso con respecto a los objetivos del estudio. De esta manera, se definieron las siguientes categorías: 

1. Solicitudes
2. Lugar del equipo técnico
3. Lugar del trabajador social
4. Coordinación
5. Creación de discurso psicosocial o social
6. Temas
7. Tareas futuras o no realizadas hasta la fecha

El presente artículo responde básicamente a las categorías dos y tres, que forman parte del análisis de la situación desde el pasado a la actualidad y cartografían la situación profesional del trabajador social en el ámbito de justicia. Como hablamos de una realidad compleja, las referencias escaparán a la codificación.

Para desarrollar los discursos de los entrevistados y miembros de los grupos de discusión triangulares, se dividieron los datos en tres categorías principales que agrupan las dimensiones que nos interesan:

- Historia y situación actual. Debates de interés.

- "Importancia" de los equipos psicosociales.

- Lugar del trabajador social en el ámbito de justicia, una topografía incierta.

Estos tres temas responden, en parte, al objetivo general de la tesis y a los primeros cuatro objetivos específicos de la investigación general.

\section{Análisis de resultados}

La forma en que se va a desarrollar la exposición de lo investigado será desde el análisis de resultados. Los textos de los discursos se irán añadiendo a pie de página para ilustrar el análisis. También el texto conversará con las referencias legales que acompañan el discurso y con la teoría que pueda corroborar cada análisis, considerando la característica del estudio de explorar, develar, de caminar en terreno inédito, con escaso discurso previo. 


\section{Historia y situación actual. Debates de interés}

El discurso de un juez de Barcelona da cuenta de los inicios de la tarea pericial en el año 1982. En el Real Decreto 1322/81 de 3 de julio se produjo la creación de los juzgados de familia en España y, posteriormente, se contrataron los primeros equipos psicosociales. ${ }^{3}$

Los inicios profesionales se caracterizan por constituirse en un proyecto provisional dentro de la administración pública, con todas las carencias de medios que esa situación producía (laborales y de integración en la norma ya sea la concreta familiar o la procesal). Lo curioso es que esa situación "fantasmal" no se ha resuelto tras treinta años de trabajo continuado, ya hace diez años, tal como lo diagnosticó el abogado Zarraluqui, un jurista especializado en el fuero de familia.

El discurso continúa detallando nuevos datos de interés que sirven para dibujar el lugar de los técnicos. Hay pocos jueces que hayan seguido la trayectoria de los equipos psicosociales y este discurso detalla la evolución desde un lugar externo, de ahí su interés. ${ }^{4}$

El Magistrado de Familia González del Pozo (2007, p. 432) destaca igualmente la falta de ubicación legal o reglamentaria del colectivo: "no existe norma legal o reglamentaria alguna que discipline el funcionamiento de estos equipos ni aclare el estatuto jurídico de los miembros de estos equipos, ni su régimen de responsabilidades e incompatibilidades".

Las referencias legales más cercanas corresponden a la Ley de Enjuiciamiento Civil española, cuando se refieren a la prueba pericial, pero no corresponden exactamente a la forma procesal de reclamarla y a la tarea posterior a realizar, sino que sirven de referencia. El Código Civil español hace referencias puntuales, al igual que la ley que establece el llamado Código Civil Catalán, la cual recoge una reseña mínima que el colectivo ha visto decepcionante.

Eran momentos en los que los profesionales entraban en un mundo ajeno y eran recibidos como ayuda, pero dentro de unos valores y un lenguaje

3 “En el año 82 que provisionalmente se instituyeron para auxiliar a los juzgados y a los tribunales" (Primer Juez de Barcelona entrevistado, comunicación personal, 26 de enero de 2012).

4 "Yo recuerdo que en un intento de hacer un trabajo sobre cometido profesional que debían hacer, habló del año 92 o 93, encontramos que la única regulación que había era el convenio colectivo" (Primer Juez de Barcelona entrevistado, comunicación personal, 26 de enero de 2012). 
que debían aprender. Los equipos psicosociales empezaron a estudiar los procedimientos judiciales y a intentar su integración en ellos. El ajuste era difícil, pero había interés mutuo en la creación de un léxico común y en la creación de protocolos de trabajo que orientaran la labor. La situación era distinta en unos lugares u otros, en cada juzgado. ${ }^{5}$

En Cataluña y Madrid existe una visión distinta en relación con los equipos psicosociales y el quehacer de un psicólogo o un trabajador social. ${ }^{6}$ Además, parece que en Cataluña se configuró una estructura, un proyecto administrativo autonómico propio y especializado tras las transferencias. ${ }^{7}$

La evolución de esta breve historia en Cataluña termina con una reseña a la situación actual (momento de la entrevista, enero de 2012), en la que la Generalitat de Cataluña ha remitido a los jueces una carta en la que les informa que los servicios del Servei d'Assessorament Técnic en l'Ambit de la Familia (SATAF) se reservan únicamente para los procedimientos en los que se haya concedido justicia gratuita a las partes. Los jueces estiman que esto constituye un retroceso y en el momento de las entrevistas se aprecian enfadados y preocupados por esta nueva situación pericial. ${ }^{8}$

La historia de los equipos psicosociales también se recoge en los discursos de los técnicos. Hay una postura reivindicativa de algún técnico que empezó esta tarea en Barcelona y explica las características del trabajo que se hacía en los inicios. ${ }^{9}$ También hay una idea general (en esa primera

5 "Lo que sí ha existido siempre es una gran heterogeneidad en los cometidos técnicos, según el juez, según el juzgado, según la comunidad autónoma" (Primer Juez de Barcelona entrevistado, comunicación personal, 26 de enero de 2012).

6 "En Madrid tuvimos entrevistas con jueces, con trabajadores sociales para ver cómo se podía hacer aquello. Nos encontrábamos con jueces que pedían para el pleito principal un informe del psicólogo y para las medidas provisionales o para la ejecución el mismo informe, pero del trabajador social, como si fuera de inferior categoría, no se diferenciaba. Y bueno, esa es la impresión que tengo, que todavía no ha terminado de solucionarse" (Primer Juez de Barcelona entrevistado, comunicación personal, 26 de enero de 2012).

7 "En unas circunstancias en Barcelona que ya se habían hecho las transferencias, se dio un paso importante que fue la creación de un equipo psicosocial único para toda Barcelona y luego para toda Cataluña, y eso permitió ciertas especialidades. Hubo una época dorada, en la que todo eso se intentó racionalizar" (Primer Juez de Barcelona entrevistado, comunicación personal, 26 de enero de 2012).

8 "Ahora resulta que volvemos a la inexistencia de normas, y al disparate. Hemos recibido una nota de la Generalitat que el equipo psicosocial solo intervendrá cuando exista declaración de justicia gratuita, que si no hay justicia gratuita, no intervendrá el equipo psicosocial" (Primer Juez de Barcelona entrevistado, comunicación personal, 26 de enero de 2012).

9 "El planteamiento vino dado por la historia previa de formación. Desde el primer momento vimos que la historia tenía que ser psicosocial, que los equipos estaban formados por psicólogos y 
época, la década de los años ochenta) de cómo tiene que ser el trabajo, de que los procesos de familia no deben buscar culpables e inocentes, sino una nueva forma de organización familiar, a ser posible, contando con la colaboración de los padres. ${ }^{10}$

En la primera etapa de Barcelona hay un grupo de profesionales que explican los orígenes y los cambios de situación que se dieron a partir de la Ley Orgánica 5/2000 de Responsabilidad Penal del Menor, que produjo el traslado de todos los trabajadores de los juzgados de familia a las fiscalías de menores y la externalización del servicio de los juzgados de familia. En esa descripción del pasado, además de cierta amargura, hay detalle de la ideología profesional que sostenía el trabajo y de la colaboración con los jueces. ${ }^{11}$ La colaboración con los jueces en un proceso ilusionante y conjunto tomó distintos rumbos en la aventura catalana, cuando se produjo la privatización del servicio. ${ }^{12}$ También se debate un concepto de trabajo en discusión actualmente, como es la idea sistémica. Los profesionales antiguos de Barcelona defienden esta idea inicial. ${ }^{13}$

Por otro lado, los técnicos de Madrid entrevistados no refieren una historia única en un sentido unitario y reivindicativo, pero sí se recoge por algún trabajador social la vieja función de los seguimientos de las visitas

asistentes sociales, por algo, porque era el tipo de intervención que se tenía que hacer en el campo de la familia, de diagnóstico" (Octavo Psicólogo de Barcelona entrevistado, comunicación personal, 31 de enero de 2011).

10 "La orientación siempre iba encaminada a que los niños tenían padre y madre, y tenían que conservar a ambos. Esto costó mucho que fuera aceptado, porque la idea que había era de buenos y malos, uno era bueno y otro era malo, entonces la idea de que era un conflicto de dos adultos en la que se implicaba a los menores y había que dejarlos aparte, y que los adultos lo tenían que resolver ellos, pero que en cualquier caso no tenían que dejar de ver a uno de ellos, esto costó" (Octavo Psicólogo de Barcelona entrevistado, comunicación personal, 31 de enero de 2011).

11 "En lo que hacíamos. Entonces lo que se hacía más importante era considerar al padre y a la madre, porque en las separaciones, cortas y es fácil que se produzcan estas separaciones de enfrentamiento, en lugar de poder compartir la paternidad. A mí me parece que lo importante era poder ayudar a tener esta opinión, que tampoco se consiguió del todo pero... Los jueces, su filosofía se adaptó muy bien a este nivel, la experiencia fue positiva con todos los jueces y todos los equipos" (Cuarto Trabajador Social de Barcelona entrevistado, comunicación personal, 31 de enero de 2011).

12 "Sabes que pasó, que hubo el momento de la privatización, que sí nos apoyaron los jueces, pero no pasó nada, la vida sigue" (Cuarto Trabajador Social de Barcelona entrevistado, comunicación personal, 31 de enero de 2011).

13 "Supongo que por esto de las entrevistas conjuntas. La concepción sistémica. Era lo que parecía al principio, que éramos los únicos que hacíamos este tipo de intervención, como más duro, pero más correcto" (Cuarto Trabajador Social de Barcelona entrevistado, comunicación personal, 31 de enero de 2011). 
entre padres e hijos, como una situación laboral ilusionante que superaba horarios y ámbito funcional, y que termina con la aparición de los Puntos de Encuentro Familiar (PEF, servicios externos encargados de la ejecución de los regímenes de visitas complejos). ${ }^{14}$

La situación legal del colectivo no se ha concretado y definido, y las transferencias a las comunidades autónomas de la competencia de justicia han complicado más la situación. Los profesionales de Madrid y Barcelona son empleados públicos de los respectivos gobiernos autonómicos y se distribuyen en Barcelona en el ya citado SATAF, y en Madrid adscritos a los distintos juzgados de familia de la capital o al Tribunal Superior de Justicia de Madrid, con destino en las localidades con juzgados competentes en asuntos de familia. ${ }^{15}$

Otra cuestión polémica y a debatir es el reparto desigual de profesionales en los equipos psicosociales, cuestión que no es baladí, porque rompe la igualdad y el espíritu de equipo e introduce la disputa y la discusión en torno a la pregunta sobre qué profesional es más necesario, debate ajeno al concepto de interdisciplinariedad y más cercano a ideas únicas del trabajo.

El devenir laboral de los equipos psicosociales ha dado lugar a múltiples polémicas y debates que continúan hoy, quizás las más significativas son las que recogen la distinta opinión de los que piensan que los equipos psicosociales son peritos y aquellos que ven a estos equipos como figura auxiliar de los jueces, más allá de lo pericial. La figura pericial integraría a los equipos en la forma procesal (dentro de la fase probatoria y con presencia o audiencia letrada en cada acto del equipo) y con las obligaciones que recoge la Ley de Enjuiciamiento Civil; por su parte, la concepción auxiliar llevaría a una ayuda y asesoramiento continuo del juez durante toda la tramitación del expediente judicial. Esta segunda figura se acerca a lo que la Ley Orgánica 5/2000, de Responsabilidad Penal del Menor atribuye a sus equipos técnicos, y disminuye la garantía procesal según sus críticos,

14 "Hasta que aparecieron los PEF, las psicosociales eran psicosociales, los seguimientos que los correspondían a los trabajadores sociales, hasta que llegaron los PEF" (Segundo Trabajador Social entrevistado de Madrid, comunicación personal, 23 de febrero de 2011).

15 "A la práctica, otra cosa es el discurso sobre si estamos más o menos metidos en la norma o no, o la importancia o la discusión que puede haber. A la práctica, yo creo que el equipo psicosocial en los juzgados tiene un papel importante" (Segundo Trabajador Social entrevistado de Barcelona, comunicación personal 27 de enero de 2011). 
al producirse la intervención del equipo en la visión del juez, sin que las partes lo conozcan y puedan intervenir. ${ }^{16}$

El mismo juez fundamenta esta opinión en las leyes españolas que imitan, en su opinión, a las francesas. ${ }^{17}$

El otro debate que se aprecia en los discursos de los distintos profesionales es sobre el destino del trabajo psicosocial, hacia quién se dirige el trabajo: a los jueces o a las familias. La cuestión puede parecer obvia y resolverse dirigiéndose a ambos, pero su solución no es tan sencilla pues la discrepancia existe y marca un estilo y una forma de trabajar. ${ }^{18}$ Hay planteamientos de trabajo en los que se percibe una necesidad de planificar una intervención con mayor o menor profundidad. La necesidad de abordar los conflictos que nos plantean familias que están en crisis. ${ }^{19}$ También influye en el juez y en la familia el problema de la falta de recursos y la lista de espera. ${ }^{20}$

Pero el debate se plantea con mayor interés en los dos grupos de discusión de trabajadores sociales. Esta investigación recoge una parte de los discursos seleccionados por su interés: a quién ayudamos y a qué. En ocasiones hay respuestas escépticas y desilusionadas, ${ }^{21}$ pero también hay una cierta esperanza en que el trabajo llegue a la familia y signifique algo en su evolución tras la crisis. En este y en el otro grupo de discusión de trabajadores sociales judiciales, se plantea que la relación de las familias con los

16 "Había una radical diferencia con Madrid, pues al equipo psicosocial se le daba la consideración de peritos, mientras que en Barcelona se le daba la consideración de auxiliares del juez" (Primer Juez entrevistado de Barcelona, comunicación personal, 26 de enero de 2012).

17 "El dictamen psicosocial como prueba diferente, que no hay que engañarse, aquí el legislador copió a Francia, donde hay jueces de familia que tienen auxiliares que les ayudan en ciertos sentidos y donde no llega el juez, llegan los auxiliares" (Primer Juez entrevistado de Barcelona, comunicación personal, 26 de enero de 2012).

18 "Yo sí, hay cosas que forman parte del trabajo y hay que asumir, vives en el conflicto y con el conflicto. El trabajo que tenemos de asesorar a jueces es una parte del trabajo. Hay una segunda parte que es el trabajo directo con la familia, una cosa es mi cliente y otra es un usuario" (Cuarto Psicólogo entrevistado de Barcelona, comunicación personal, 27 de enero de 2011).

19 "Los cambios yo creo que son a medio plazo, no espero que ninguna familia cambie aquí, pero sí que la familia piense en lo que aquí se trabaje y eso pueda promover algún cambio. Es lo que yo me digo a mí misma para considerar que este trabajo es útil" (Cuarto Psicólogo entrevistado de Barcelona, comunicación personal, 27 de enero de 2011).

20 "Y esto es difícil también para el juez que lo que necesita en familia es una respuesta ya, en dos o tres semanas como mucho, pero no en tres meses. Y el volumen que tenemos de casos nos impide dar esa respuesta" (Quinto Psicólogo entrevistado de Barcelona, comunicación personal, 28 de enero de 2011).

21 "Yo creo que les ayudamos en una sola cosa: a motivar la sentencia" (Primer Trabajador Social, Grupo de discusión 2, 24 de mayo de 2012). 
profesionales del trabajo social judicial supone un momento del procedimiento en el que el usuario, la familia, ve cómo se humaniza su proceso. ${ }^{22}$

\section{La "importancia" de los equipos psicosociales}

La historia de la labor psicosocial en los juzgados de familia sirve para dibujar el mapa que se busca en este estudio, a la vez que plantea alguno de los grandes debates de la profesión. Pero el lugar central de la tarea psicosocial lo plantean los profesionales cuando se les pregunta por la importancia de los equipos psicosociales. Se recogen los discursos de jueces, psicólogos y trabajadores sociales entrevistados, y también fragmentos del debate en grupo de los trabajadores sociales. Con ellos se va rotulando con lugares comunes el mapa definitivo del territorio profesional.

Los jueces ven importante la tarea psicosocial, valoran la ayuda que les han prestado los profesionales que han formado parte de su equipo de trabajo desde una postura asesora y de colaboración. ${ }^{23}$ Más allá de la adhesión personal y profesional, se plantea el valor de la ayuda concreta para clarificar cuestiones familiares en las que el juez no tiene conocimientos técnicos para diferenciar; también se aprecia su utilidad para llegar a acuerdos y el uso de los textos técnicos para construir argumentos jurídicos o conciliar posturas encontradas a priori.

Los jueces reconocen la importancia de la labor psicosocial por el nivel de profundidad en el conocimiento de las familias, lo que incrementa el conocimiento del juez. ${ }^{24} \mathrm{El}$ argumento de la imparcialidad es muy expuesto

22 "A comprender el problema que está pasando a la familia, qué visión tiene cada miembro y en qué sentido se puede orientar el grupo, para que esa visión sea la más adecuada" (Segundo Trabajador Social, Grupo de discusión 2, 24 de mayo de 2012).

"Yo creo que vale, eso es lo final, pero es verdad que humaniza un expediente, una familia" (Tercer Trabajador Social, Grupo de discusión 2, 24 de mayo de 2012).

"Humaniza a la familia, pero al juez..." (Primer Trabajador Social, Grupo de discusión 2, 24 de mayo de 2012).

"Yo creo que se humaniza a la familia, y se ven cosas de la familia, es verdad que luego termina que justifica para quien es la custodia y punto... pero también hay diálogo, hay diálogo con los jueces..." (Tercer Trabajador Social, Grupo de discusión 2, 24 de mayo de 2012).

23 "A mí me ha ayudado mucho pero porque he tenido suerte con las personas que he tenido en el equipo y yo creo que también me he involucrado con ellas" (Primer Juez entrevistado de Barcelona, comunicación personal, 26 de enero de 2012).

24 "Me ayuda a desarrollar mi pensamiento, es como si mi pensamiento se expandiera y to- 
en las distintas entrevistas. Se valora también el conocimiento integral de la familia y la posibilidad que tienen los equipos psicosociales judiciales de explorar toda la familia. ${ }^{25}$

Los psicólogos judiciales de Barcelona entrevistados opinan que se ha llegado a un buen lugar y que los equipos psicosociales son importantes en los procesos de familia. En el SATAF se ha realizado un estudio sobre la influencia de los informes en las sentencias judiciales y los resultados presentan una notable trascendencia de las propuestas técnicas. Sin embargo, se apunta la esperanza que había en que el llamado "Código Civil catalán" introdujese la figura de los equipos psicosociales en el articulado y se aprecia decepción por la presencia marginal en la Disposición Adicional Sexta punto 4 del Libro II de este texto (Ley 25/2010, de 29 de julio, del libro segundo del Código civil de Cataluña, relativo a la persona y la familia). Por otro lado, se incide en la importancia de los informes psicosociales en los procesos de familia. Además, los psicólogos dan razones que ya recogían los jueces, como la imparcialidad. ${ }^{26}$

Los psicólogos refieren un cambio en el objeto del trabajo, los jueces buscan cuestiones jurídicas y los asuntos de familia tienen otro tipo de argumentos. $^{27}$

Hay una aceptación importante del equipo psicosocial, pero algún psicólogo apunta diferencias entre unos y otros profesionales; es un asunto en

mara en cuenta una serie de circunstancias materiales que por la brevedad del juicio no se pueden tener en cuenta, o por las pruebas" (Tercer Juez entrevistado de Barcelona, comunicación personal, 27 de enero de 2012)

25 "Pero es lo que estamos comentando, dudas de la objetividad y la parcialidad, muchas veces te llegan informes que no han visto a toda la unidad familiar" (Primer Juez entrevistado de Madrid, comunicación personal, 10 de noviembre de 2010).

26 "Yo pienso que, a nivel de confianza, confían mucho e incluso delegan bastante. Esto en lo que respecta a derivaciones, cuando les llega el informe, yo creo que nos dan mucha validez, se hizo un estudio y nos hacen caso en un noventa por ciento, las propuestas de equipo" (Segundo Psicólogo entrevistado de Barcelona, comunicación personal, 27 de enero de 2011).

"Yo soy poco optimista, básicamente porque creo que te han contado la reforma del libro segundo del Código Civil de Familia, y teníamos la expectativa de que el equipo nuestro saliera por algún sitio, sale recogido en una disposición adicional, creo que es la novena" (Séptimo Psicólogo entrevistado de Barcelona, comunicación personal, 28 de enero de 2011).

27 "Nosotros hablamos más de tiempo, de emociones, de variables, de factores que están incidiendo y que entienden, porque tienen formación específica en familia, pues no se manejan y se dan ciertos desequilibrios. Creo que tenemos un estatus importante dentro de la Administración de Justicia" (Primer Psicólogo entrevistado de Barcelona, comunicación personal, 27 de enero de 2011). 
el que se reconoce entre profesionales el trabajo común, pero se observa una peor imagen de los trabajadores sociales como colectivo profesional menos reconocido. ${ }^{28}$

Los psicólogos judiciales de la Comunidad Autónoma de Madrid insisten en esta trascendencia del informe psicosocial para los jueces en procedimientos de familia; no lo hacen desde la objetividad de un estudio de investigación realizado, pero sí, desde la experiencia diaria de relación dentro del propio juzgado del que forman parte más integrada. ${ }^{29}$

Algún psicólogo incide en el trabajo conjunto y opina que la labor auxiliar que llama "de asistencia", no es correcta. Este es un punto a debatir: los profesionales de Barcelona, incluido algún juez, creen en la labor asesora y auxiliar. En Madrid hay profesionales que funcionan en esa línea, mientras otros defienden un modelo más puro de lo pericial, menos contaminado de la cercanía que da el estar integrado en la dinámica del juzgado. ${ }^{30}$ Los trabajadores sociales judiciales de Barcelona refuerzan la misma opinión de un lugar destacado de los equipos psicosociales en la administración de justicia de familia, a pesar de la escasa regulación legal. ${ }^{31}$

Los profesionales del trabajo social judicial de Madrid inciden en ese lugar de privilegio de los equipos psicosociales en la administración de la justicia de familia. Ven la ayuda a la familia como primordial y consideran que la menor o mayor importancia depende del juzgado concreto en el que se trabaja partiendo de la satisfacción general. ${ }^{32}$

28 "Nos quieren, están satisfechos con nuestro trabajo, pero se quejan de tiempo, se quejan de que a veces no respondemos a lo que ellos nos piden. Creo que a los psicólogos nos tienen más reconocidos que a los trabajadores sociales, creo que los trabajadores sociales habéis defendido poco vuestra disciplina" (Sexto Psicólogo entrevistado de Barcelona, comunicación personal, 28 de enero de 2011).

29 "Para mí, demasiado importante, me gustaría ser menos importante" (Primer Psicólogo entrevistado de Madrid, comunicación personal, 29 de noviembre de 2011).

30 "Yo estoy satisfecha con el nivel de consideración que han dado al trabajo que hemos hecho (...) Creo que también he tenido la suerte de trabajar con jueces que han sido respetuosos con nuestro espacio, no pidiendo cosas impropias, de asistencia y tal, que generasen situaciones confusas, porque luego nos piden el peritaje, si han pedido ha sido "off the record", y fuera de un caso concreto sobre tal tema o tal otro" (Cuarto Psicólogo entrevistado de Madrid, comunicación personal, 29 de noviembre de 2011).

31 "A la práctica, otra cosa es el discurso sobre si estamos más o menos metidos en la norma o no, o la importancia o la discusión que puede haber. En la práctica, yo creo que el equipo psicosocial en los juzgados tiene un papel importante" (Segundo Trabajador Social entrevistado de Barcelona, comunicación personal, 27 de enero de 2012).

32 "Yo siempre me he sentido bien, no sólo ahora, porque siempre me he sentido valorada en 
Hay posturas de distintos trabajadores sociales judiciales en las que se plantean dudas, partiendo de la visión general de evaluarse desde la importancia y trascendencia que los equipos psicosociales tienen en cada procedimiento. Relativizan el lugar de los equipos por su poco tiempo en funcionamiento, a la vez que se denuncia que se ha dejado de ayudar a las familias por la demanda del sistema judicial. También, hay unas opiniones más realistas, por ejemplo, la de los trabajadores sociales de Madrid, que refieren de forma relativa su imagen dentro del sistema judicial, a la vez que desdibujan esa importancia que se ha recogido en los testimonios de otros profesionales. Ellos expresan con amargura la pérdida de la ayuda a las familias como una pobreza. ${ }^{33}$ Uno de los grupos de discusión de trabajadores sociales también debate sobre la importancia de los equipos psicosociales y su conclusión denuncia un exceso de responsabilidad. ${ }^{34}$

\section{El lugar de los trabajadores sociales judiciales. Una topografía incierta.}

La Guía de Actuación de los Trabajadores Sociales judiciales de la Comunidad de Madrid (2006) recuperaba las viejas funciones de estos en la administración de justicia:

El trabajador que con titulación universitaria de Diplomado en Trabajo Social o Asistente Social, bajo la dependencia funcional del órgano al que está adscrito, lleva a cabo su intervención profesional informando

el sentido. Cuando me han preguntado ha sido con interés de que lo que voy a ofrecerles les va a ayudar". (Primer Trabajador Social entrevistado de Madrid, comunicación personal, 16 de diciembre de 2010).

33 "Ofrecer un espacio dentro del ámbito judicial y dentro de la disputa, pero que es algo diferente. Somos distintos: pueden hablar, se pueden expresar, les podemos hacer devoluciones, dar pautas. Creo que cada vez se ayuda menos, pero no por la profesión, sino por lo que es el sistema judicial en sí" (Tercer Trabajador Social de Madrid, comunicación personal, 25 de mayo de 2011).

34 "Añado que me sorprende, mi experiencia es que si se me tiene en cuenta, que en ocasiones he tenido la experiencia de pensar que aunque no se me paga para eso, el que yo hiciera un informe pronunciado, eso iba a hacerse, esa responsabilidad, porque luego quedaba como al margen el resto del procedimiento" (Trabajador Social 1, Grupo de discusión 1, 29 de marzo de 2012). "Yo coincido también. La responsabilidad que se toma como equipo es muy fuerte, que tienes que tomar las decisiones y que el propio juez las puede asumir como propias" (Trabajador Social 1, Grupo de discusión 1, 29 de marzo de 2012). 
y asesorando técnicamente a los Tribunales, juzgados, Fiscalías y Órganos Técnicos en materia de su disciplina profesional. Actuarán tanto a nivel individual como interprofesional, elaborando los informes sociales solicitados por el órgano mencionado, así como la colaboración con los restantes miembros de los Equipos Técnicos para el desarrollo de las mencionadas funciones (2006, p. 11).

La primera entrevista que puede ayudar a trazar ese lugar indeterminado de la profesión en el ámbito judicial, se realizó a un profesor de la Facultad de Trabajo Social de la Universidad Complutense de Madrid, el cual apunta las coordenadas para situar el trabajo social en el mundo de la justicia y desarrolla argumentos para su integración en el mundo académico. ${ }^{35} \mathrm{El}$ mundo de la justicia ha dejado de manejarse con certezas y verdades absolutas y se dirige hacia lo discrecional. En esa nueva situación el profesor encuentra que la justicia de familia, el derecho de familia, ha evolucionado desde las decisiones prefijadas en las normas, a la evaluación de cada familia y al acuerdo posterior de las decisiones. En este tipo de justicia el trabajo social como disciplina de las ciencias humanas y sociales tiene que adoptar un rol decisivo. ${ }^{36}$ Las relaciones familiares tienen un carácter complejo, multifactorial y en continuo movimiento; lo que antes estaba claro, no lo es tanto con las nuevas familias. Las migraciones, las familias reconstituidas, ensambladas, como las define Grossman y Martínez Alcorta

35 "Tiene un papel determinante de carácter pericial, es decir, como un especialista en la determinación de los circunstancias sociales que concurren en algunos supuestos, dado que la justicia tiene la pretensión de adaptar la ley a la realidad. Es un instrumento de ajuste y de adecuación, fundamentalmente, de manera que los jueces pueden ver que lo que no ven en la sala, está a nivel de otros profesionales como por eso los médicos, tanto psiquiatras como médicos de tipo físico, es un instrumento profesional especializado" (Profesor entrevistado, comunicación personal, 14 de marzo de 2010).

36 "La justicia ha tenido tradicionalmente una prevención ante los contenidos valorativos, de manera que en el orden de incorporación de la prueba al procedimiento, ha sido la medicina física primero, luego vino la medicina psíquica y después los factores que son más evanescentes, como los condicionantes sociales, de manera que en el orden de llegada a la pericia son de los últimos (...) El trabajo social llevaría a unos resultados análogos; la cuestión es que el componente valorativo es mayor que en otras circunstancias, pero es totalmente cierto que la psicología tendría unos mismos, o si se trata de un sociólogo o de un antropólogo, el trabajo social lo que hace es ajustar un conjunto de disciplinas que tiene un desarrollo teórico en otros ámbitos, a situaciones humanas y familiares concretas, y por tanto, tiene las ventajas de todas estas ciencias, sus límites, sus contradicciones, e incluso sus cambios de axiomas" (Profesor entrevistado, comunicación personal, 14 de diciembre de 2010). 
(2000), las familias con progenitores del mismo sexo..., todo ello complica cada decisión judicial y hace más necesario cualquier estudio de la familia. ${ }^{37}$

Pero la discrecionalidad e interpretación de las situaciones familiares no debe partir del vacío, ni expresarse libremente y sin criterios. La valoración pericial debe hacerse desde el rigor científico y metodológico, del cual debe dotarse si no lo posee el trabajo social judicial. ${ }^{38}$ La dotación metodológica debe venir del mundo académico, en el cual se reconoce una ausencia significativa de los planes de estudio. Este crecimiento académico dará rigor y método al trabajo social judicial y desde este lugar será más fácil la integración total en el mundo de la justicia y la ayuda al juez. ${ }^{39}$

La definición del concepto de prueba en el campo sociofamiliar es lo más importante para el profesor, quien critica la función auxiliar del trabajo social en la justicia. El trabajo de ayudante del juez sin estar integrado en la fase procesal de la prueba supone una usurpación y ataca el principio de oralidad de la prueba y su necesaria publicidad para las partes..$^{40}$

Añade una cuestión que puede complicar ese carácter riguroso del que hablaba antes, pues explica, que en el ámbito de justicia, como en tantos otros, el trabajador social en su ejercicio depende de su propia personalidad más que en otras profesiones. ${ }^{41}$

37 "Me explico, sobre cuestiones que antes se daban por hechos, como las custodias de los niños, de los menores; hoy día hay posibilidades alternativas para dar un margen a la decisión judicial amplia, según gana en amplitud el procedimiento judicial, la opinión en la que debe sustentarse tal pronunciamiento empieza a ser más necesaria. Va a ser como unos vasos comunicantes, que en este caso no crece uno detrás de otro, sino que van a crecer todos, simultáneamente. El futuro es de una altísima importancia del trabajo social entiendo, porque el juez, a medida que tiene más discrecionalidad, va a necesitar forzosamente en qué apoyarse" (Profesor entrevistado, comunicación personal, 14 de diciembre de 2010).

38 Lo que debería exigirse al trabajador social, insisto, es el rigor en el método, al margen de que luego sus conclusiones puedan ser discutibles, pero que el método aplicado sea impecable, minucioso, con soportes documentales o tablas, con criterios, con antecedentes, que tenga esto; porque si ya existe la sospecha de carecer o, más bien, de tener demasiados contenidos valorativos, sería estruendoso que, además, no tuviera aparato (Profesor entrevistado, comunicación personal, 14 de diciembre de 2010).

39 "Lo que estoy notando progresivamente es una necesidad de compensar un atributo que se les está dando cada vez más de la discrecionalidad, con un soporte científico de sus decisiones" (Profesor entrevistado, comunicación personal, 14 de diciembre de 2010).

40 "Podría implicar una usurpación, se traslada la idea y debe ser así que tomó una decisión asesorado por peritos, en este caso sin sometimiento a un criterio formal, sin estar en un periodo de prueba, en un ámbito concreto, yo veo que lo podría dotar de cierta inseguridad jurídica" (Profesor entrevistado, comunicación personal, 14 de diciembre de 2010).

41 "Entonces, es que hay trabajadores sociales que han creado un rol fundamental dentro de la institución en la que están" (Profesor entrevistado, comunicación personal, 14 de diciembre de 2010). 
La justicia necesita de profesionales de lo complejo, como son los trabajadores sociales. Para ello y para su formación se requiere de la presencia del trabajo social judicial en los programas universitarios y de una investigación y estudio continuo, que den ese rigor al trabajo social judicial. ${ }^{42}$

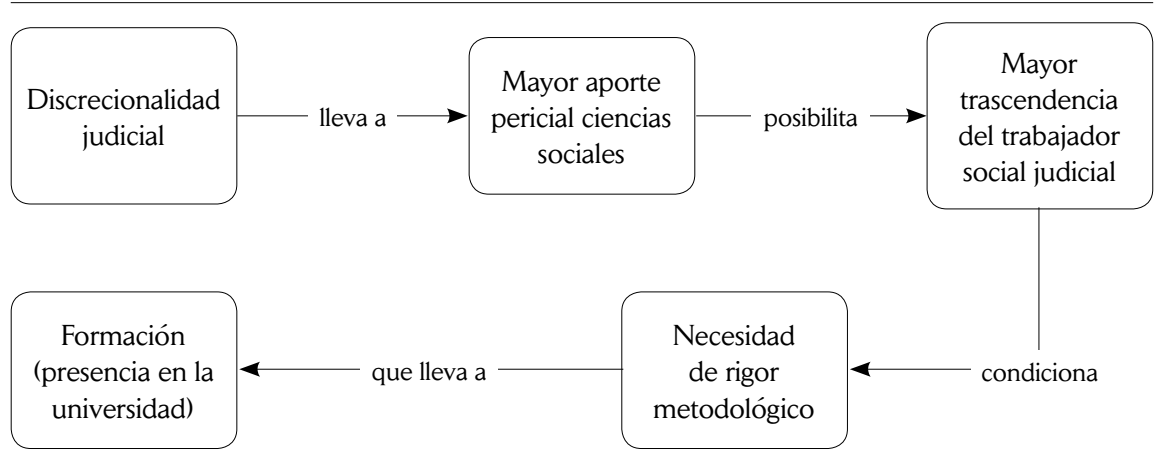

Figura 2. Trascendencia del trabajador social en el ámbito de justicia

Fuente: elaboración propia.

El lugar que ocupan los trabajadores sociales judiciales empieza a dibujarse; los profesionales entrevistados, testigos de la tarea de evaluación socio-familiar, crean un mapa de situación. Los jueces de Barcelona exponen su desconocimiento, en general, sobre la figura del profesional, que luego matizan, ya que en algún caso se refieren a la ocupación de este profesional en los aspectos materiales o en los no psicológicos; también se habla del estudio de los horarios familiares como una función propia. En algún caso, se pide implicación para resolver los casos y no dejarlos en un lugar de nadie por la voluntad de no ofender a las partes en los informes. Se expresa, además, un cierto desinterés en dilucidar el lugar concreto del profesional, ya que entienden que es tarea del SATAF hacer la distinción.

42 "Igual que va camino de la privatización de las cosas y la línea que la discrecionalidad de decisiones, como eso es imparable y el juez no tiene formación ni tiene por qué tenerla para sacar esos datos ni ese artilugio, va a tener que tener cerca igual que tiene psicólogos y médicos, igual que los peritos arquitectos tiene cada vez más presencia de las cosas. Y luego un cambio cultural de los abogados, donde la argumentación jurídica ha dejado paso al trabajo probatorio" (Profesor entrevistado, comunicación personal, 14 de diciembre 2010).

"Eso hace que se trabaje la prueba con mucho mayor rigor y con mayor preocupación, conozco cómo funcionan las cosas a mediados de los 80 y el rigor de la práctica de la prueba era menor que ahora y eso pues es, y eso va a favor del interés de los trabajadores sociales" (Profesor entrevistado, comunicación personal, 14 de diciembre de 2010). 
En este caso se recogen dos ideas interesantes para el análisis global: por un lado, el establecimiento del seguimiento como función del trabajador social, función alejada de lo pericial y en la que se pide implicación, y por el otro, la distinción del servicio psicosocial de otro servicios. En otros discursos los jueces diferencian las funciones por defecto: lo que no requiere "análisis psicológico". ${ }^{43}$

Igualmente, piden que el profesional valore la unidad familiar y no sea un mero descriptor de la dinámica, a pesar de que las valoraciones aluden, casi siempre, a decisiones judiciales, cuestión polémica en la que hay profesionales que creen que debe ser el juez el que diga qué progenitor debe tener la custodia y el trabajador social valorar capacidades y habilidades de los padres. ${ }^{44}$

Los jueces de Madrid han conocido el trabajo en expedientes concretos con informes socio-familiares y exponen de forma interesante la importancia que le dan a los mismos y describen las tareas que le corresponden en su opinión..$^{45} \mathrm{El}$ detalle de la ausencia del trabajador social de las ratificaciones (juicios), es significativo. ${ }^{46}$

43 "Yo le pido que se implique en el tema. (...) la realización de seguimientos que se acuerdan en la sentencia constituye una tarea agotadora, que creo que hay tendencia a extinguirla, aunque sea en perjuicio de las personas implicadas" (Segundo Juez entrevistado de Barcelona, comunicación personal, 27 de enero de 2012).

Nosotros no distinguimos mucho del trabajador social. Se supone que el propio equipo se distribuye las funciones $\mathrm{y}$, como la firma es conjunta, no se distingue mucho en que participa uno $u$ otro, aunque hay cosas en las que sí, por ejemplo las peticiones materiales, la vivienda, los hábitos de vida, los horarios, esas cuestiones que no requieren estudio psicológico. El trabajador social es el que lleva esa parte, pero realmente no solemos distinguirla, el resultado está firmado por los dos y santas pascuas (Tercer Juez entrevistado de Barcelona, comunicación personal, 27 de enero de 2012).

44 "Al trabajador social o psicólogo del SATAF se le pide que oiga a las dos partes, que tenga los antecedentes del procedimiento, que contacte con los profesionales para conocer sobre la vida de las familias, desde el punto de vista del centro docente, tutor y psicólogos si están tratando a los padres o al menor, y también que el informe que hagan no sea sólo descriptivo, sino que tenga una parte, de consideraciones y conclusión, en la que se decante respondiendo a lo que se le pide, a lo que las partes piden: la obtención de la guarda y custodia o las visitas. Es una cuestión que tiene que decidir el juez, pero que las propias partes, cuando piden la pericial del equipo psicosocial, piden un pronunciamiento concreto, que no es el equipo psicosocial, es el juez el que tiene que decidir, pero lo piden" (Cuarto Juez entrevistado de Barcelona, comunicación personal, 27 de enero de 2012).

45 "Creo que dentro del equipo para temas de familia, lo que venís haciendo, debería encargarse más de las entrevistas con toda la red social y escolar de la familia, el colegio, los propios servicios sociales, la parte más suya, la parte de las visitas a las viviendas" (Segundo Juez entrevistado de Madrid, comunicación personal, 29 de noviembre de 2010).

46 "Antes era equipo en su conjunto; el psicólogo venía a ratificarse y el trabajador social quedaba un poco en la sombra. Luego a posteriori los seguimientos de las resoluciones judiciales 
Existe otra opinión que vincula los datos más objetivos a la tarea sociofamiliar, pero sigue siendo interesante que muchos jueces ya conozcan que los trabajadores sociales son expertos en las redes familiar y social del individuo y que pueden desarrollar un diagnóstico y pronóstico sobre la situación de la familia y su futuro. ${ }^{47}$ La visión se va concretando y enriqueciendo, quizás sea una generalización decir que no conocen lo que se hace por parte del trabajador social, cuando se recogen argumentos acertados. ${ }^{48}$

Los otros profesionales que son entrevistados y aportan su visión sobre este lugar indeterminado y "fantasmal" son los propios trabajadores sociales. Los trabajadores sociales de los juzgados de Barcelona y Madrid son los protagonistas directos de esta investigación. En el caso barcelonés, se hace evidente el trabajo conjunto de muchos profesionales, el debate entre profesionales y la "lucha" profesional de los trabajadores sociales por ocupar su lugar, que en ocasiones es un debate entre compañeros, y en otras, forma parte del ejercicio de la profesión de perito en la sala de juicio con los letrados de las partes.

Los distintos profesionales de Barcelona insisten en la capacidad de psicólogos y trabajadores sociales para hacer su trabajo diario individualmente. ${ }^{49}$

La competencia de los trabajadores sociales para evaluar una familia, realizar un informe socio-familiar y defenderlo en un juicio se plantea como un argumento común, pero no por ello se deja de reconocer la riqueza del trabajo conjunto con los psicólogos. ${ }^{50}$

los hacía el trabajador social, y cuando habéis venido a ratificar, no ha habido problemas" (Segundo Juez entrevistado de Madrid, comunicación personal, 29 de noviembre de 2010).

47 "Sí, lo que te he dicho, veis antecedentes, los recursos que tiene la persona alrededor, si está bien apoyada familiarmente, el tipo de trabajo, los apoyos que puede tener si después de la separación se queda solo, apoyos familiares, los abuelos... esos son datos más objetivos que el análisis psicológico" (Tercer Juez entrevistado de Madrid, comunicación personal, 20 de diciembre de 2010).

48 "El trabajador aparte de su tarea fundamental, que es la de participar en la elaboración de los informes, tiene un trabajo fundamental, para mí, en el seguimiento de las familias. (...) Sí, como progresa para bien o para mal, el trabajador social para mi gusto es esencial" (Cuarto Juez entrevistado de Madrid, comunicación personal, 23 de febrero de 2011).

49 "No, yo creo que la mayoría de demandas que vienen dadas por los juzgados son de valoración de los regímenes de visitas, tanto de guardas y custodia, como de guardas y custodias compartidas. Yo entiendo que en estos casos tanto un psicólogo, como un trabajador social pueden dar respuesta perfectamente a este tipo de demandas" (Primer Trabajador Social entrevistado de Barcelona, comunicación personal, 27 de enero de 2011).

50 "Yo creo que, de hecho, al menos aquí que hay un trabajo conjunto de psicólogos y trabajadores sociales, a pesar de las diferencias, a pesar de las críticas, a pesar de muchos pesares, el equipo 
Aunque existe este trabajo común, cuando el trabajador social presenta su informe socio-familiar hay cuestionamientos desde los letrados de las partes. Este es un argumento de defensa que usa el profesional de la parte "perjudicada" en el informe, pero los cuestionamientos por la profesión se hacen con mayor frecuencia en los casos de informes sociales. ${ }^{51}$

Los trabajadores sociales de los juzgados de la Comunidad de Madrid tienen una lógica diferente y alguna "herida" común en lo profesional. Centran su definición del rol del trabajo social en el ámbito funcional, aunque critican la excesiva determinación de competencias, porque entienden que el campo es muy complejo e indeterminado para hacer divisiones claras.

En principio hay una división: la del profesional que hace la pericial y la del profesional que la revisa. Es una división funcional que en este primer discurso se define como antigua. Si se compara con otros países, se aprecia que en Argentina hay una adscripción similar de responsabilidad profesional del trabajador social en la evolución de las visitas, con riesgos profesionales:

La designación de trabajadores sociales en las causas donde el régimen de visitas es el motivo central del conflicto suele acompañarse de la expectativa de jueces y otros funcionarios judiciales de ejercer alguna forma de control, límite y censura en el comportamiento de los padres incumplidores (...) Limitar la acción profesional a aquel acto de control puede producir una intervención desacertada y, en algunas ocasiones, reforzar las situaciones de conflicto o exclusión (Robles, 2004, p. 99).

La cuestión es si esto es un mecanismo de control o una ayuda. ${ }^{52}$ Foucault (1994) sitúa en los técnicos la función de vigilar y controlar a los

es hoy lo que es y hace lo que hace y como lo hace, porque hay dos disciplinas. (...) Un informe conjunto es un informe que desde el principio hasta el final se hace conjuntamente. Te puede parecer menos operativo, pero las entrevistas se hacen conjuntas, el informe se hace conjunto. Sí puede haber una cosa concreta que esto es más de trabajo social o de psicólogo, pero todo es conjunto, es aprendizaje y enriquecimiento de las dos profesiones" (Segundo Trabajador Social entrevistado de Barcelona, comunicación personal, 27de enero de 2011).

51 "Sí que me siento a gusto, pero me he encontrado en algún juicio que me ha tocado ir a declarar, cuando los abogados, utilizan mil estrategias y cuando ven que el informe es de una trabajadora social, intentan hacer lo posible para desacreditar el informe, me he encontrado unas situaciones embarazosas, porque formo parte de un equipo, del sistema" (Tercer Trabajador Social entrevistado de Barcelona, comunicación personal, 28 de enero de 2011).

52 "De lo que recuerdo de esa época, nosotros los trabajadores sociales funcionábamos mucho con las visitas. Eran el 90\% del trabajo que hacíamos, era la ejecución de las sentencias que 
usuarios, a los pacientes, quienes realizarían una función perversa de ayuda al control estatal de las conductas. En ese sentido, los seguimientos de los sistemas de visitas quizás sirvan al poder judicial para controlar las conductas de los padres, más allá de las sentencias. La dependencia de los padres del sistema judicial también se alargaría más allá de la decisión judicial. Todo ello en materia de derecho privado.

El discurso también profundiza en los problemas que ocasiona el intervenir (a través del seguimiento), y ser perito en un procedimiento posterior. También en los cambios históricos producidos en el trabajo social judicial. Estos cambios tienen que ver con la aparición en los años noventa de APROME, en Valladolid durante 1994, y de los Puntos de Encuentro Familiar (PEF), que se extendieron por toda España. Actualmente, se aprecia una involución en este aspecto como consecuencia de la reducción de servicios públicos por la situación de crisis económica. ${ }^{53}$ La labor del trabajador social judicial también aporta la derivación a los recursos del entorno que se pueden trabajar previamente.

Los discursos van exponiendo los aspectos más trascendentes de la labor del trabajador social-judicial, la metodología, la evolución de los recursos, las funciones pericial y asesora, y la polémica función de ayuda a las familias.

A partir de aquí, es importantísima la comunicación y coordinación con los demás actores profesionales: el psicólogo dentro de la tarea de equipo y el juez. ${ }^{54}$ Otro aspecto que es polémico es que hay profesionales que consideran que no se debe decir todo lo que se sabe, porque hay datos o cuestiones que pueden perjudicar a la familia. Los jueces piden implica-

previamente se habían puesto en un proceso de separación, esas sentencias no se llevaban a cabo desde hacía mucho tiempo. Con lo cual, se había cronificado una situación de un progenitor de no ver a su hijo, desde hacía bastante tiempo. Pero curiosamente yo entendía o entendíamos en ese momento se tenía que hacer todo lo posible para que aquello funcionara" (Primer Trabajador Social entrevistado de Madrid, comunicación personal, 16 de diciembre de 2010).

53 "¿Qué ha cambiado? Que ahora hay unos puntos de encuentro y antes no los había, ¿quiénes eran los que supervisaban a los regímenes de visitas entonces? Los trabajadores sociales" (Primer Trabajador Social entrevistado de Madrid, comunicación personal, 16 de diciembre de 2010).

54 "Luego, la tarea de coordinación con el profesional que trabajamos, habitualmente trabajamos con el psicólogo y hay que saber compartir... y, bueno, a veces los límites no están claros y es cierto que hay que trabajar. Yo creo que es muy rico el trabajo en equipo y es algo que tenemos para valorarlo y mantenerlo" (Tercer Trabajador Social entrevistado de Madrid, comunicación personal, 25 de noviembre de 2011). 
ción y claridad. Se incide en el estudio de las redes y de lo más concreto: de lo material. ${ }^{55}$

Además de esto, existe una opinión de mezcla y pérdida de límites entre lo que puede y debe evaluar un profesional u otro. Los campos de la evaluación de una familia son mayoritariamente psicosociales, lo que provoca perplejidad en muchos profesionales que ven cómo algunas instituciones y asociaciones solicitan la división funcional estricta. ${ }^{56}$

\section{Reflexiones y conversaciones con la teoría}

Este estudio se hace para develar, explorar y descubrir el verdadero lugar de los trabajadores sociales del ámbito de la justicia. El campo está poco desarrollado en España. Anteriormente se habló de las funciones y la metodología, de nuestra relación con la justicia y de la forma de trabajar en equipo. Pero nadie midió el lugar del trabajador social del ámbito de justicia en todo este devenir de más de treinta años. La profesora Brezmes (2008) sí investigó sobre la realidad del trabajador social en general y su situación en España, y es interesante conocer sus conclusiones sobre las razones del lugar de esta profesión en la estructura científica del país. También Ponce de León (2011) indagó en la escasez de investigación y documentación científica de la disciplina del trabajo social.

Por otro lado, desde la perspectiva de campo de Bourdieu, los investigadores Fortich y Moreno (2012) refieren que:

Los conceptos claves en la teoría de Bourdieu son campo, habitus y capitales. El campo es una estructura donde se da una lucha, de unos agentes que han interiorizado y asumido plenamente las reglas de juego -habitus- y donde hay unos capitales específicos, es decir un ente sistema

55 "Difícil, de memoria. Pienso que la función exclusiva del trabajador social dentro del equipo es desarrollar el estudio de la parte de las redes sociales, cómo influyen en la familia, si las hay, y si no, exponer lo que supone la carencia" (Cuarto Trabajador Social entrevistado de Madrid, comunicación personal, 25 de mayo de 2011).

56 "En concreto aportar, es que yo esto lo veo muy mezclado entre psicólogo y trabajador social" (Quinto Trabajador Social entrevistado de Madrid, comunicación personal, 25 de mayo de 2011). 
de posiciones de poder para retener o expulsar a quiénes no asumen sus códigos (Fortich y Moreno, 2012).

Desde esta posición, se puede medir la forma en que los trabajadores sociales del ámbito de justicia se han convertido en agentes en lucha, que han interiorizado las normas, e incluso las han hecho propias y, de alguna forma, como auxiliares y agentes del poder judicial se han convertido en detentadores de poder. Faltaría, para una mayor integración, generar un discurso y método propio y una mayor integración en el fuero de familia, a través de su presencia en la ley. El propio Bourdieu (2000) avisaba, sin embargo, que la tecnificación del ejercicio del derecho puede: "ir desplazando la frontera con los profanos por medio de la elevación del formalismo jurídico" (p. 160).

Quizás lo que aporte la profesión al derecho sea más una humanización que una tecnificación, por lo que, en este punto, el Trabajo Social, tal como lo afirmaría la profesora Beatriz Cohen, busca en la justicia del fuero de familia: "humanidad, empatía, humildad, sensibilidad cultural, involucramiento personal y cuidado de las personas" (Citada en Mahbubani, 2008).

Se puede buscar una opinión externa a la realidad española como la de la trabajadora social colombiana, profesora Quintero, quien señala:

En países como España (pionera en el tema desde la década de los 90) no se duda sobre la importancia que tienen los "peritos sociales judiciales" para reforzar los argumentos jurídicos en un proceso litigioso (...) De igual manera, es reconocido el valor que tienen los trabajadores sociales como los profesionales más indicados para estudiar y valorar el ambiente en que se encuentra inmerso el individuo y también sus proyecciones futuras y propuestas de mejora, lo cual puede ser utilizado en el ámbito judicial en caso necesario (Quintero, 2010).

\section{Conclusiones}

Una vez analizados los discursos de los protagonistas en las entrevistas y grupos de discusión, y en relación con la teoría revisada, las conclusiones sugeridas por el análisis de datos son: 
- Los equipos psicosociales en España tienen una vida corta (desde 1982) y una historia en la que, progresivamente, se han ido integrando en los procedimientos judiciales de familia. Hoy están extendidos por todo el territorio nacional con distinta vinculación con la administración y con diferente organización.

- No existe una regulación clara de su función y de su integración en el procedimiento legal.

- Los jueces entienden que su labor es necesaria aunque hay discrepancias sobre el rol que deben tener respecto al juez y las familias.

- Los propios profesionales discrepan sobre la función auxiliar o pericial, incluso sobre si se deben cubrir ambas. La ayuda debe darse al juez, pero los trabajadores sociales se sienten vinculados por su propia naturaleza profesional a la ayuda a las familias. Cualquier planteamiento pericial puro se quedaría en el conocimiento y diagnóstico, sin planificar ni implementar la acción. También cabe discutir si la relación de ayuda impide la objetividad del perito.

- La falta de regulación legal y la adscripción a distintos entes autonómicos o estatales ha creado diferentes formas de realizar el trabajo y situarse ante los jueces y ante las familias. El estudio sugiere la diferencia entre Madrid y Barcelona como los dos centros de trabajo pericial con mayor número de profesionales en España. El trabajo catalán ha sido pionero en una forma de entender la profesión desde la teoría sistémica, con un fuerte apoyo a la coparentalidad y una visión positiva de la parentalidad, sin resolver los procedimientos del fuero de familia declarando culpables o inocentes. En Madrid la situación es más variada, ya que la práctica reside en multitud de centros y no está unificada como en Barcelona. Cada equipo depende de uno o pocos juzgados y se establece una relación de cercanía tanto con el juez, como con el juzgado, que favorece la integración en la propia dinámica de la institución.

- Los trabajadores sociales sufren esa indeterminación funcional de los propios equipos, a la que añaden el desconocimiento de la profesión en el ámbito jurídico y su escaso prestigio social. Pero desarrollan su trabajo de forma práctica y han contribuido paritariamente con los psicólogos a la implantación de los equipos psicosociales. Se aprecia en el colectivo de trabajadores sociales barceloneses una mayor asertividad respecto a sus funciones y lugar en el juzgado. 
- La mejora de la situación de los trabajadores sociales judiciales pasa por una mayor presencia en las instituciones del trabajo social, particularmente la académica (la universidad), y el desarrollo de un rigor metodológico y una formación en el mismo.

\section{Referencias}

Alberdi, I. (1995). Informe sobre la situación de la familia en España. Madrid: Ministerio de Asuntos Sociales.

Alberdi, I. (1999). La nueva familia española. Madrid: Taurus.

Alcázar, R. (2014). Diseño de una escala para la evaluación de la custodia compartida en el ámbito judicial. Azarbe, 3, pp. 271-277.

Alday, M. R., Ramjlak, N.L., \& Nicolini, G.M. (2001). El trabajo social en el servicio de justicia. Buenos Aires: Espacio.

Alonso, L.E. (1994). Sujeto y discurso: El lugar de la entrevista abierta en las prácticas de la sociología cualitativa. En J.M. Delgado \& J. Gutiérrez. Métodos y técnicas cualitativas de investigación en ciencias sociales (pp. 225-240). Madrid: Síntesis.

Beltrán, M. (2007). Cinco vías de acceso a la realidad social. En M. García Ferrando, J. Ibáñez, E Alvira, F. ( $3^{\mathrm{a}}$ Ed.). El análisis de la realidad social. Métodos y técnicas de investigación (pp. 15-55). Madrid: Alianza.

Bourdieu, P. (2000). Elementos para una sociología del campo jurídico. En P. Bourdieu \& G. Teubner. La fuerza del derecho. Bogotá: Uniandes.

Brezmes, M. (2008). El trabajo social en España. Murcia: Editum.

Davis, L. (2007). See you in Court. London: Jessica Kingsley Publishers.

Fortich, M.P., \& Moreno, A. (2012). Elementos de la teoría de los campos de Pierre Bourdieu para una aproximación al derecho en América Latina: Consideraciones previas. Verba luris 27, pp. 47-62.

Foucault, M. (1994). Vigilar y castigar. Madrid: Siglo XXI Editores.

Gómez, F., G. Soto, R. (2015). Nuevas tareas, nuevos lugares del trabajo social judicial en España. Serviço Social \& Sociedade, 121, pp. 10-23.

González del Pozo, J. (2007). Medios de prueba. En E. Hijas (Director). Los procesos de familia: una visión judicial. Madrid: Colex.

Grosman, C., \& Martínez Alcorta, I. (2000). Familias ensambladas. Buenos Aires: Editorial Universidad. 
Guía de Actuación de los Trabajadores Sociales en el ámbito de la administración de justicia de la Comunidad de Madrid. (2006) Madrid: Vicepresidencia Segunda y Consejería de Justicia e Interior de la Comunidad de Madrid.

Hijas Fernández, E. (2007). Los procesos de familia. Una visión judicial. Madrid: Colex. Iglesias de Ussel, J., \& Ayuso, L. (2007). Permanencia y cambio en la familia española en el siglo XXI. En F. Gómez, F. Intervención social con familias, (pp.3-24). Madrid: Mc Graw-Hill.

López Ordiales, J.J. (2008). Custodia compartida. Cuestiones procesales. En Saravia González, A.M., (Coord.), La jurisdicción de familia: especialización. Ejecución de resoluciones y custodia, (pp. 249-312). Madrid: Consejo General del Poder Judicial, Escuela Judicial, Cuadernos de Derecho Judicial no 147.

Mahbubani, R. (2008, 13 de mayo). Artemisa. Los fallos de las mujeres juezas. Recuperado de http://rpsaba.blogspot.com.es/2008/05/justicia-y-gnero.html Maschi, T., E Killian, M.L. (2009). Defining Collaborative Forensic Social Work with diverse populations. En T. Maschi, C. Bradley, \& K. Ward (Eds.), Forensic Social Work. New York: Springer.

Murillo, S., E Mena, L. (2006). Detectives y camaleones: el grupo de discusión. Madrid: Talasa.

Ponce de León, L. (2011). Investigación y trabajo social: Investigando en el pasado las claves del futuro de la profesión. $5^{\circ}$ Congreso de Trabajo Social de Madrid. Madrid: Colegio Oficial de Trabajadores Sociales de Madrid.

Quintero, A.M. (2010). Pruebas psicosociales en derecho de infancia, adolescencia y familia. Informe final de Investigación. Universidad de Antioquía.

Robles, C. (2004). La intervención pericial en Trabajo Social. Buenos Aires: Espacio. Roldán, E. (1998). Los grupos de discusión en la investigación en Trabajo Social y Servicios Sociales. Cuadernos de Trabajo Social, 11, pp. 133-144.

Ruíz Rodríguez, P. (2004). El trabajador social como perito judicial. Zaragoza: Certeza. Simón, M. (2010). Aportaciones del trabajo social a la pericial de familia. En J.J Tapia (Dir.), Custodia compartida y protección de menores, (pp. 177-210), Madrid: Dykinson.

Solé, R. (2009). Redes complejas. Barcelona: Tusquets.

Val, C. E Gutiérrez, J. (2005). Prácticas para la comprensión de la realidad social. Madrid: Mc Graw-Hill.

Valles, M. (2007). La grounded theory y el análisis cualitativo por ordenador. En García Ferrando, M., Ibáñez, J. E Alvira, F., El análisis de la realidad social. Métodos y técnicas de investigación (3 ${ }^{\text {a }}$ edición) (pp. 575-603). Madrid: Alianza.

Vasilachis de Gialdino, I. (2006). Estrategias de investigación cualitativa. Barcelona: Gedisa. 


\section{Legislación española}

- Real Decreto 1322/81 de 3 de Julio por el que se crean los Juzgados de Familia.

- Ley 30/1981, de 7 de julio por la que se modifica la regulación del matrimonio en el Código Civil y se determina el procedimiento a seguir en las causas de nulidad, separación y divorcio.

- Ley $1 / 2000$, de 7 de enero, de Enjuiciamiento Civil.

- Ley Orgánica 5/2000. reguladora de la Responsabilidad Penal del Menor

- Ley 15/2005, de 8 de julio por la que se modifican el Código Civil y la Ley de Enjuiciamiento Civil en materia de separación y divorcio.

- Ley 25/2010, de 29 de julio, del libro segundo del Código civil de Cataluña, relativo a la persona y la familia. 